\title{
Detection of Alul Endonuclease Activity by Using Double Stranded DNA-Templated Copper Nanoclusters
}

\author{
Ji Su Yang and Jongback Gang* \\ Department of Chemistry, Gachon University, Sungnam 1342, Republic of Korea
}

Received: March 1, 2021 / Revised: March 31, 2021 / Accepted: May 26, 2021

\begin{abstract}
Restriction endonucleases play an important role in molecular cloning, clinical diagnosis, and pharmacological drug studies. In this study, DNA-templated copper nanoclusters (DNA-CuNCs) were used to detect AluI endonuclease activity due to their high fluorescence emission and rapid synthesis of DNA-CuNCs under ambient conditions. Results showed that AluI activity was detected in a highly sensitive manner at low concentrations of AluI endonuclease by the fluorescence intensity of DNA-CuNCs. Additionally, its inhibition was monitored in the presence of daidzein under optimal conditions.
\end{abstract}

Keywords: Fluorescence assay, DNA-CuNCs, Alul endonuclease assay

Restriction endonuclease enzymes hydrolyze the phosphodiester bond of double-stranded DNA at a specific recognition sequence. They have been utilized for molecular cloning, clinical diagnosis, antimicrobial and antiviral drugs, and pharmacological drug studies [1-4].

Traditional assays, such as radioactive and antigenic labeling [5, 6], gel electrophoresis [7], and colorimetric methods [8] have been established to detect restriction endonuclease activities. However, these methods have some intrinsic drawbacks, such as being time-consuming, insensitive, laborious, discontinuous, and requiring isotope labeling [9]. Fluorescence-based methods involving fluorescence resonance energy transfer-based assays [10-12] and signal amplification-based fluorescence methods [13-18] have been developed for detection of endonuclease activity [19]. These fluorescence methods generally required labeling DNA with fluorescence dyes and the labeled fluorophores influenced the binding affinity and specificity of the probe affecting the outcome [20]. It is essential to develop fluorescence methods not

\section{*Corresponding author}

Tel.: +82-31-750-5409, Fax: +82-31-750-5389

E-mail: jbgang@gachon.ac.kr involving the labeling probes and reducing high expense for endonuclease assays.

Recently, DNA-templated copper nanoclusters (DNACuNCs) show the large Stokes shift, which is a favorable for the elimination background signals interference in complex biological systems [21]. Furthermore, DNACuNCs display high fluorescence intensities at low reactant concentrations and can be rapidly synthesized (<10 min) under ambient conditions [21, 22]. Recent reports have showed that AluI-sensitive sites in nonmalignant cells were relatively more exposed by chromatin reorganization than those in malignant cell [23]. Therefore, AluI endonuclease was useful for clinical diagnosis to distinguish normal cells from malignant human breast cells [24].

This study measured AluI endonuclease activity and its inhibition in the presence of daidzein using hairpin DNA-CuNCs. The oligomer used in this study is 5'ATATATAGCTATATAGGGGGGGGGGGCTATATA GCTATATAT-3'. The detection strategy for AluI endonuclease activity was described in Scheme 1. The oligomer contained an AluI recognition sequence (5'-AGCT3') and two signal sequences (5'-ATATATA-3',5'-TATATA3) in its stem region. Therefore, the hairpin DNA acted 


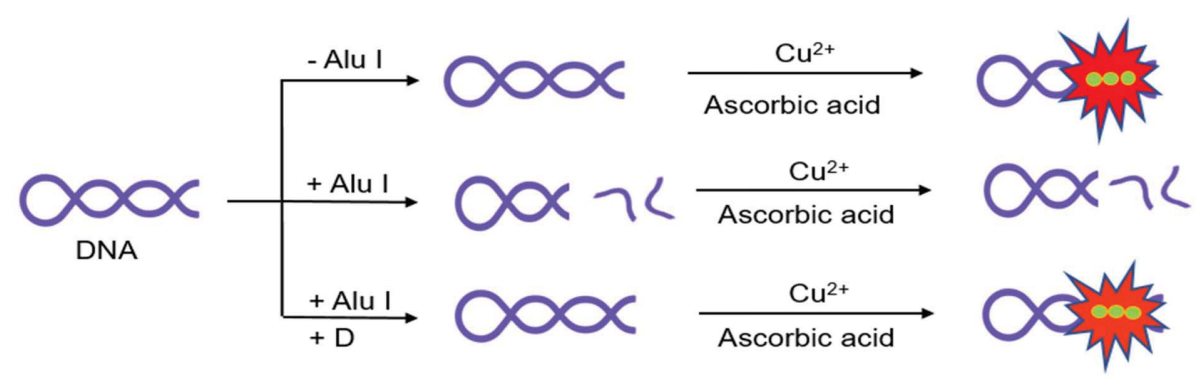

Scheme 1. Schematic diagram of the Alul endonuclease assay. Reactions were conducted with hairpin DNA either in the absence (top) or presence (middle) of Alul endonuclease. In the bottom, restriction digestion was conducted with hairpin DNA in the presence of Alul and daidzein (D).

as a substrate of AluI endonuclease and the specific template for $\mathrm{Cu}$ nanoclusters formation. As shown in Scheme 1, AluI endonuclease hydrolyzed a phosphodiester bond of dsDNA in its recognition sequence (middle). Since AluI digestion produced shorter hairpin DNA and $8 \mathrm{bp}$ dsDNA, this short dsDNA would be dissociated into ssDNA at $37^{\circ} \mathrm{C}\left(\mathrm{T}_{\mathrm{m}}\right.$ value was $4.8^{\circ} \mathrm{C}$, calculated by OligoAnalyzer, integrated DNA Technologies, USA). In contrast, short hairpin DNA contained 5'-ATATAT-3' in its stem region, but sequence-dependent fluorescence enhancement was not detected. In the absence of the AluI endonuclease (top), hairpin DNA was not digested. However, hairpin DNA was not digested in the presence of the AluI and daidzein (bottom). After DNA$\mathrm{CuNCs}$ were synthesized by adding $\mathrm{Cu}^{2+}$ and ascorbate, fluorescence intensity was measured using Gemini XPS Microplate Reader (Molecular Devices, USA) at an emis-

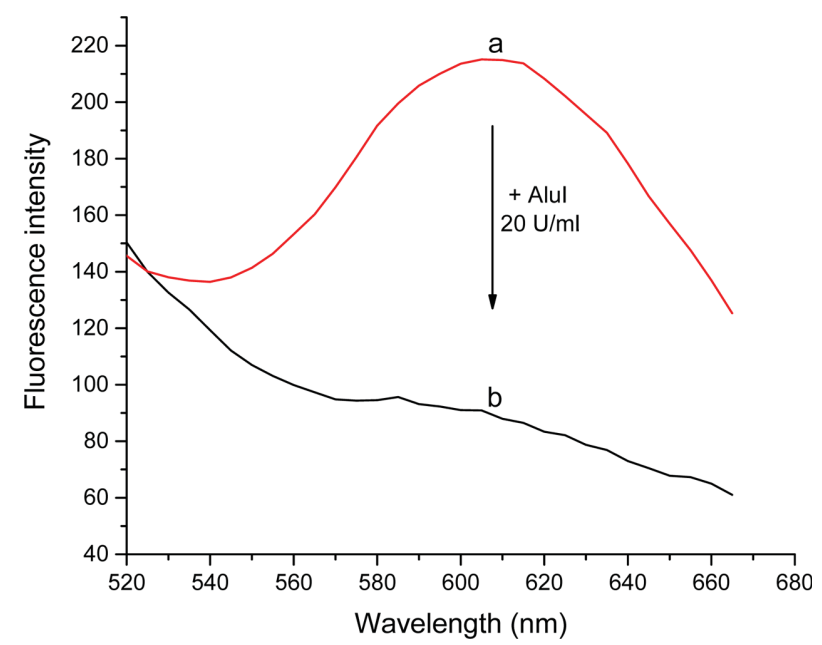

Fig. 1. Fluorescence spectra of DNA-CuNCs were monitored from 520 to $660 \mathrm{~nm}$ either in the presence (b) or absence (a) of $20 \mathrm{U} / \mathrm{mL}$ Alul endonuclease. sion wavelength of $610 \mathrm{~nm}$ and at an excitation wavelength of $340 \mathrm{~nm}$.

In order to verify the strategy formulated for AluI detection, fluorescence emission spectra were obtained under different conditions (Fig. 1). Fluorescence spectra were recorded from 540 to $660 \mathrm{~nm}$ in the presence (b) or absence (a) of AluI endonuclease. At $50 \mathrm{U} / \mathrm{mL}$ AluI endonuclease, the fluorescence intensity decreased dramatically to $41 \%$ of that in the absence of the AluI endonuclease. Therefore, treatment with AluI endonuclease led to a significantly decrease in fluorescence intensity from 215 to 89 at low concentration of hairpin DNA $(0.5 \mu \mathrm{M})$. It was confirmed that the assay described in this study using hairpin DNA-CuNCs was sensitive for the detection of restriction endonuclease activity. A recent study [21] reported that the fluorescence intensity decreases to $28 \%$ of that in the absence of endonuclease at $100 \mathrm{U} / \mathrm{mL}$ of EcoRI endonuclease $(1.0 \mu \mathrm{M}$ dsDNA). The detection assay for endonuclease activity described in this study was highly sensitive at low DNA concentration.

The plot of F/Fo against AluI concentrations is shown in Fig. 2. Fo and F represent the fluorescence intensities in the absence (Fo) or presence (F) of AluI endonuclease, respectively. Results showed that the fluorescence intensities decreased rapidly at low concentrations of AluI endonuclease ranging from $0.2 \mathrm{U} / \mathrm{mL}$ to $5 \mathrm{U} / \mathrm{mL}$. In contrast, fluorescence emission of hairpin DNA-CuNCs decreased slowly as the AluI endonuclease increased from $10 \mathrm{U} / \mathrm{mL}$ to $50 \mathrm{U} / \mathrm{mL}$.

According to recent clinical research [24], AluI endonucleases are employed with high sensitivity to diagnose normal and malignant human breast cells according to the resistance of AluI endonuclease digestion. 


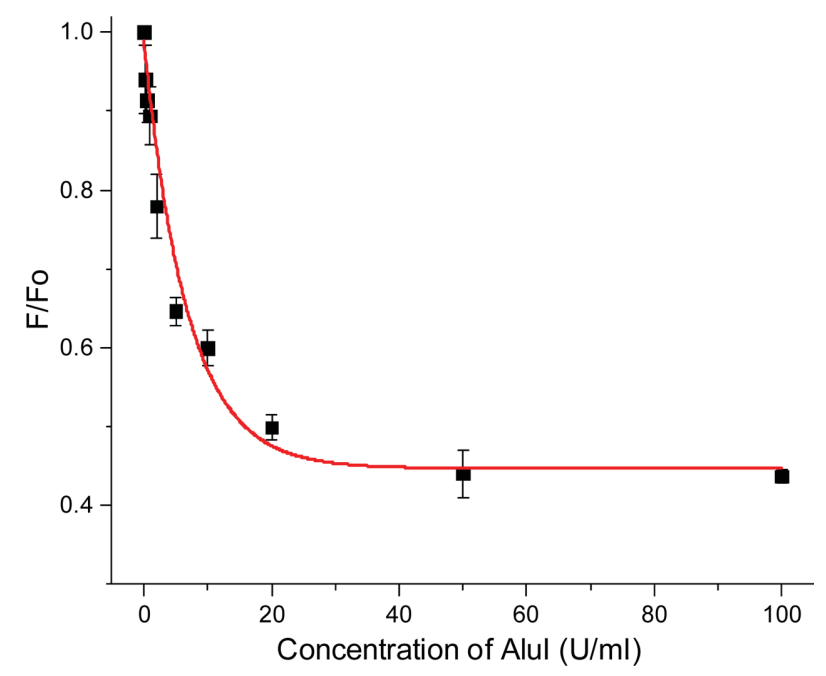

Fig. 2. Plot of $F / F_{0}$ against various concentrations of Alul endonuclease from 0.2 to $100 \mathrm{U} / \mathrm{mL}$. $F$ and $F_{0}$ indicate fluorescence intensities in the presence and absence of Alul, respectively.

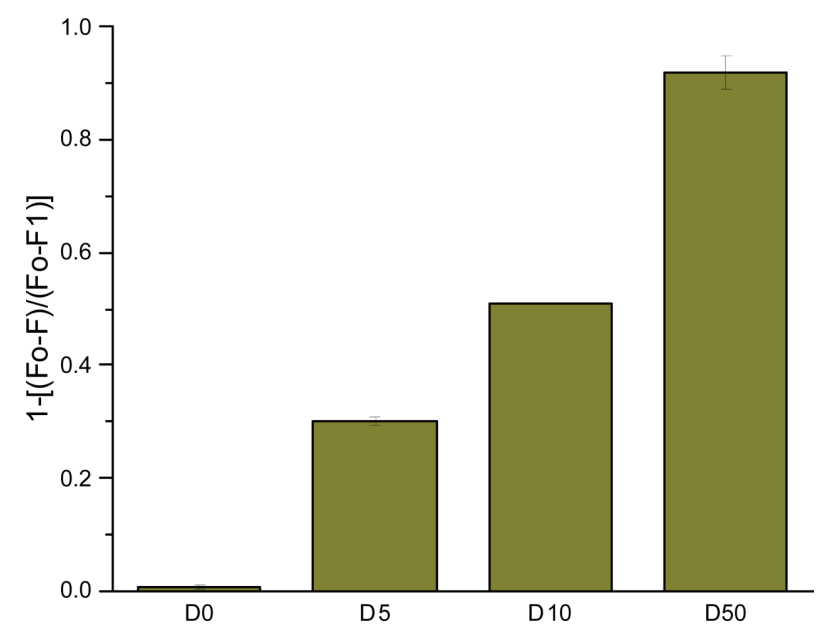

Fig. 3. Inhibition of Alul endonuclease $(20 \mathrm{U} / \mathrm{mL})$ by daidzein. The degree of inhibition, $1-\left[\left(F_{0}-F\right) /\left(F_{0}-F_{1}\right)\right]$ was plotted against daidzein concentration. D5, D10, and D50 represent 5, 10, and $50 \mu \mathrm{M}$ of daidzein, respectively, in the presence of Alul endonuclease.

To study the inhibition of AluI endonuclease activity, endonuclease activity was measured at various concentrations of daidzein. The inhibition reaction was conducted using AluI endonuclease $(50 \mathrm{U} / \mathrm{mL})$ and duplex DNA $(0.5 \mu \mathrm{M})$ in the presence of inhibitor. Daidzein was added to the reaction mixture before performing enzymatic digestion, and the reaction mixture was incubated at $37^{\circ} \mathrm{C}$ for $1 \mathrm{~h}$. The extent of AluI inhibition by daidzein, $\left(1-\left(\mathrm{F}_{0}-\mathrm{F}\right) /\left(\mathrm{F}_{0}-\mathrm{F}_{1}\right)\right)$ was measured in the presence of different concentrations of daidzein. $\mathrm{F}_{\mathrm{o}}$ and $\mathrm{F}_{1}$ represent fluorescence intensities without daidzein either in the absence or presence of AluI respectively (shown in Fig. 3). F represents fluorescence intensity at different concentration of daidzein at $50 \mathrm{U} / \mathrm{mL}$ of AluI. In the present study, $\left(1-\left(F_{0}-F\right) /\left(F_{0}-F_{1}\right)\right)$ was found to be $0.3,0.51$, and 0.82 in the presence of $5,10,50 \mu \mathrm{M}$ of daidzein, respectively. This indicated that AluI activity was inhibited sensitively by increasing daidzein concentrations in this study. A recent study [21] reported that the $\mathrm{IC}_{50}$ value of 5-fluorouracil for inhibiting EcoRI endonuclease activity is approximately $64.06 \mu \mathrm{M}$ by using DNAAgNCs.

\section{Conclusion}

In this study, hairpin DNA-CuNCs were used to detect AluI endonuclease activity and its inhibition. Treatment with AluI endonuclease led to a significant decrease in fluorescence intensity at low concentrations of hairpin DNA. Our detection system is useful and highly sensitive for the detection of restriction endonuclease activity. In addition, treatment with $10 \mu \mathrm{M}$ of daidzein inhibited AluI endonuclease activity to $51 \%$ under optimal conditions.

\section{Conflict of Interest}

The authors have no financial conflicts of interest to declare.

\section{References}

1. Brueckner B, Lyko F. 2006. DNA methyltransferase inhibitors: old and new drugs for an epigenetic cancer therapy. Trends Pharmacol. Sci. 25: 551-554.

2. Shames DS, Minna JD, Gazdar AF. 2007. DNA methylation in health, disease, cander. Curr. Mol. Med. 7: 85-102.

3. Norberg P, Bergstrom T, Liljeqvist JA. 2006. Genotyping of clinical herpes simplex virus type 1 isolates by use of restriction enzymes. J. Clin. Microbiol. 44: 4511-4514.

4. Xu X, Han MS, Mirkin CA. 2007. A gold-nanoparticle-based realtime colorimetric screening method for endonuclease activity and inhibition. Angew. Chem. Int. Ed. 46: 3468-3470.

5. Harford SE, Goodall AJ. 1988. Mode of DNA cleavage by the EcoRV restriction endonuclease. Biochemistry 27: 1771-1777.

6. Jeltsch A, Fritz A, Alves A, Wolfes H, Pingoud A. 1993. A fast and accurate enzyme-linked immunosorbent assay for the determination of the DNA cleavage activity of restriction endonucleases. Anal. Biochem. 213: 234-240. 
7. Sharp PA, Sugden B, Sambrock J. 1973. Detection of two restriction endonuclease activities in Haemophilus Parainfluenzae using analytical agarose--ethidium bromide electrophoresis. Biochemistry 12: 3055-3063.

8. Song G, Chen C, Ren J, Qu X. 2009. A simple, universal colorimetric assay for endonuclease/methyltransferase activity and inhibition based on an enzyme-responsive nanoparticle system. ACS Nano 3: 1183-1189.

9. Zhao H, Dong J, Zhou F, Li B. 2017. One facile fluorescence strategy for sensitive detection of endonuclease activity using DNA-templated copper nanoclusters as signal indicators. Sens. Actuators B Chem. 238: 828-833.

10. Feng X, Duan X, Liu L, Feng F, Wang S, Li Y, et al. 2009. Fluorescence logic-signal-based multiplex detection of nucleases with the assembly of a cationic conjugated polymer and branched DNA. Angew. Chem. Int. Ed. 48: 5316-5321.

11. Deng J, Jin Y, Wang L, Chen G, Zhang C. 2012. Sensitive detection of endonuclease activity and inhibition using gold nanorods. Biosens. Bioelectron. 34: 144-150.

12. Lee C, Gang J. 2018. A Label-free detection of Ndel endonuclease activity by using DNA-templated silver nanoclusters. J. Nanosci. Nanotechnol. 18: 6339-6342.

13. Huang Y, Zhao S, Chen ZF, Liu YC, Liang H. 2011. Ultrasensitive endonuclease activity and inhibition detection using gold nanoparticle-enhanced fluorescence polarization. Chem. Commun. 47: 4763-4765.

14. Li W, Liu Z, Lin H, Nie Z, Chen J, Xu X, et al. 2010. Label-free colorimetric assay for methyltransferase activity based on a novel methylation-responsive DNAzyme strategy. Anal. Chem. 82: 1935-1941.

15. Zhao Y, Chen F, Wu Y, Dong Y, Fan C. 2013. Highly sensitive fluorescence assay of DNA methyltransferase activity via methylation-sensitive cleavage coupled with nicking enzyme-assisted signal amplification. Biosens. Bioelectron. 42: 56-61.
16. Bi S, Zhao T, Luo B, Zhu JJ. 2013. Hybridization chain reactionbased branched rolling circle amplification for chemiluminescence detection of DNA methylation. Chem. Commun. 49: 69066908.

17. Cao A, Zhang CY. 2012. Sensitive and Label-free DNA methylation detection by ligation-mediated hyperbranched rolling circle amplification. Anal. Chem. 84: 6199-6205.

18. Jia H, Li Z, Liu C, Cheng Y. 2010. Ultrasensitive detection of microRNAs by exponential isothermal amplification. Angew. Chem. Int. Ed. 49: 5498-5501.

19. Zhou Z, Du Y, Zhang L, Dong S. 2012. A Label-free, G-quadruplex DNAzyme-based fluorescent probe for signal-amplified DNA detection and turn-on assay of endonuclease. Biosens. Bioelectron. 34: 100-105.

20. Jiang XQ, Guo SM, Zhou M, Ye BC. 2014. DNA-hosted Hoechst dyes: application for label-free fluorescent monitoring of endonuclease activity and inhibition. Analyst 139: 5682-5685.

21. Zhao H, Dong J, Zho F, Li B. 2017. One facile fluorescence strategy for sensitive detection of endonuclease activity using DNA-templated copper nanoclusters as signal indicators. Sens. Acuators $B$ Chem. 238: 828-833.

22. Rotaru A, Dutta S, Jentzsch E, Gothelf K, Mokhir A. 2010. Selective dsDNA-templated formation of copper nanoparticles in solution. Angew. Chem. Int. Ed. 49: 5665-5667.

23. Maniotis AJ, Valyi-Nagy K, Karavitis J, Moses J, Boddipali V, Wang $Y$, et al. 2005. Chromatin organization measured by Alul restriction endonuclease changes with malignancy and is regulated by the extracellular matrix and the cytoskeleton. Am. J. Pathol. 166: 1187-1203.

24. Sandal T, Valyi-Nagy K, Spencer VA, Folberg R, Bissell MJ, Maniotis AJ. 2007. Epigenetic reversion of breast carcinoma phenotype is accompanied by changes in DNA sequestration as measured by Alul restriction enzyme. Am. J. Pathol. 170: 1739-1749. 